\title{
La resiliencia del mito quijotesco: Don Quijote Z o el mash-up del clásico*
}

\author{
MiRIAM BORHAM-PUYAL**
}

\begin{abstract}
Resumen
Entre las más recientes apropiaciones de Don Quijote de la Mancha cabe destacar el mash-up como un comentario a la inagotable presencia del texto de Cervantes en la cultura contemporánea. Don Quijote $Z$ (2010) proporciona un original acercamiento al texto quijotesco: en vez de reescribir a don Quijote en un contexto nuevo, reformula la obra cervantina con elementos de la literatura zombi. El mash-up quijotesco supone, por su propia naturaleza genérica, un reto a las políticas de exclusión del canon, y se muestra autorreferencial al comentar su propia posición en los márgenes de este. Lo hace al desarrollar una parodia cervantina del género $Z$, pero también de la escritura académica, al mismo tiempo que mantiene un enfoque satírico sobre los valores sociales y culturales contemporáneos. El presente artículo explora los motivos tras esta resiliencia quijotesca en la literatura y la cultura, que se hace evidente en el mash-up $\mathrm{Z}$ del clásico de Cervantes.
\end{abstract}

Palabras clave: quijotismo; mash-up; parodia; literatura Z; resiliencia; liminalidad.

Title: The Resilience of the Quixotic Myth: Don Quixote Z, or Mashing-up the Classic

\begin{abstract}
Among recent rewritings of Don Quixote de la Mancha, the mash-up stands out as a relevant comment on the enduring presence of Cervantes' text in contemporary culture. Don Quijote Z (2010) provides an original approach to the quixotic text: rather than rewriting Don Quixote into a different context, it inscribes zombie literature within the hypotext. Given its generic nature, the quixotic mash-up challenges the politics of exclusion from the canon, while highlighting in a self-referential manner its own position on its margins. It is able to develop a Cervantean parody not only of the $\mathrm{Z}$ genre, but also of scholarly

* Este trabajo se ha realizado en el marco del proyecto de investigación «Orientation: una perspectiva dinámica sobre la ficción y la cultura contemporáneas (1990 - en adelante)» (Ref. FFI201786417-P).

** Universidad de Salamanca. miriambp@usal.es / ORCID iD: https://orcid.org/0000-00028553-0769.
\end{abstract}


works, as well as to deliver a satirical approach to contemporary cultural and social values. This paper will analyse the reasons behind the quixotic resilience in literature and culture, together with its manifestation in the $\mathrm{Z}$ mash-up of Cervantes' classic.

Keywords: Quixotism; Mash-up; Parody; Z Literature; Resilience; Liminality.

\title{
Cómo citar este artículo / Citation
}

Borham-Puyal, Miriam. 2020. «La resiliencia del mito quijotesco: Don Quijote $Z$ o el mash-up del clásico». Anales Cervantinos 52: 35-55, https://oi.org/10.3989/anacervan tinos.2020.002.

\section{INTRODUCCIÓN}

Ben H. Winters, autor de títulos como Sense, Sensibility and Sea Monsters (2009) o Android Karenina (2010), escribía a propósito de la reacción que suscitan sus obras:

\begin{abstract}
There are those who cry foul every time a book with one living and one dead author turns up on the shelves. [...] There are plenty of valid answers - not least of which being that a good satire (or sequel, or adaptation, or homage, or whatever) reminds us of the enduring power of the original [...] Only respect their annoyance, for it is annoyance born of love: the same deep love for a given author that led you to write (er, co-write) your book in the first place (Winters 2010a, s. p.).
\end{abstract}

En la línea propuesta por Winters, la intención del presente artículo es contribuir al debate en torno a los híbridos aparecidos desde 2009 hasta nuestros días entre clásicos de la literatura universal y la narrativa de monstruos, entendiendo cualquier forma de reescritura -ya sea obra de autores canónicos o de fanáticos contemporáneos de los no-muertos- como un homenaje que evidencia el longevo poder del hipotexto que está siendo adaptado, y su resiliencia ante los cambios temporales, culturales o políticos.

\subsection{Qué es el mash-up literario}

El mash-up podría definirse como un género híbrido, como la fusión entre materiales u obras ya existentes para crear un trabajo o género nuevo, un concepto que se nutre de una larga tradición en el mundo del arte. Su auge en la cultura popular comenzó en el mundo de la música y los videojuegos como un crossover o híbrido de estilos y mundos narrativos, y ha encontrado 
su lugar en los más variados campos, incluyendo el cómic -con su fusión de universos textuales, como evidencian las intersecciones de las líneas argumentales de DC y Marvel, dos editoriales de cómics de superhéroes, o de Marvel y la literatura zombi, a través de los años ${ }^{1}$. . Cuando se hace referencia al mash-up literario, este género se encuentra en el umbral entre dos narrativas, e incluso contextos históricos, diferentes; se podría definir como un área liminal, entendido como una esfera de mediación activa entre sistemas culturales (Aguirre, Quance y Sutton 2000, 30). Además, esta liminalidad lo posiciona en la 'hermenéutica de la exclusión', ya que separa el canon de lo que podría considerarse literatura 'marginal' (Soto 2000, 13), pero emplea esa posición en el limen para ofrecer un comentario sobre la misma literatura, junto a la dicotomía de lo elevado y lo popular. De hecho, el mash-up, en especial el que samplea géneros tan populares como el terror o la fantasía, se excluye de los cánones académicos, pero se encuentra en el centro mismo de la cultura contemporánea, y desde esa posición permite desarrollar un acercamiento satírico a asuntos de gran calado cultural, social y político, al tiempo que parodia diversos géneros.

Por una parte, el mash-up es original en la forma que adopta su parodia. En primer lugar, porque permea textos que se consideran clásicos, es decir, obras conocidas y parte de una cultura común, con los géneros que caracterizan la cultura pop, específicamente la ficción de monstruos. De esta manera, se hace eco de tradiciones previas de subversión o travestismo de géneros o modos, como el contrafactum, dando lugar a una lectura muy relevante sobre el imperialismo y la colonización cultural, así como la idea de la propiedad colectiva de iconos, mitos y clásicos.

En segundo lugar, al emplear géneros literarios centrados en criaturas inmortales, el mash-up provee un comentario metaliterario más profundo sobre aquellos textos que, al igual que los zombis o los vampiros que ahora los pueblan, se niegan a morir, a desaparecer, y continúan viviendo bajo diferentes formas, como podría ser el caso de la novela de Cervantes, o las ya sampleadas novelas de Austen, de Tolstói, o de las hermanas Brontë. Por tanto, como bien indicó Winters, los mash-ups demuestran el imperecedero poder de estos clásicos. De hecho, al samplear textos tradicionales con nuevas narrativas populares, el mash-up crea un género híbrido que logra actualizar la agenda cultural, social, política, moral o ideológica del hipotexto para nuevas generaciones de lectores ${ }^{2}$.

1. El ejemplo más relevante sería el de Amalgam Comics, el resultado de la fusión del universo DC y el de Marvel, en el que las editoriales desarrollaron un crossover de personajes y escenarios. Para una discusión sobre los orígenes y características del género véase Borham-Puyal (2018, 13141316).

2. Fernández Porta acuña el concepto de homo sampler, el que samplea o hace un mash-up «no porque se apropie sino porque vive en su momento, sale de casa, es sensible a los signos y formas del paisaje mediático -y se cuida de señalar la procedencia de sus ideas-. La diferencia entre samplear y plagiar es bien clara, y la resistencia a reconocer la originalidad del sampleador es un prejuicio posmoderno» $(2008,161)$. 
Es posible comprobar esta característica en el fundacional Pride, Prejudice and Zombies (2009), el cual se calcula que emplea el $85 \%$ del texto original pero logra recontextualizar o colonizar el hipotexto, resaltando a través de su parodia las convenciones de la sociedad británica del XVIII y los importantes cambios sociales que se han producido desde entonces (MulveyRoberts 2014,21), o destacando el germen de esas transformaciones sociales que ya están presentes en el urtexto, por ejemplo, en lo concerniente al papel de la mujer en la esfera pública (Borham-Puyal 2018, 1317-1323). Lo mismo podría decirse de Android Karenina (2010), atribuida en 'coautoría' a Tolstói y Ben Winters, y que, según este último, busca mantener los principales temas de la obra original, incluyendo la compleja relación de la humanidad con la tecnología (Winters 2010b, s. p.).

Por tanto, el género del mash-up demuestra la afirmación de que las narrativas populares son 'eventos sociológicos' que negocian o renegocian las expectativas estéticas e ideológicas de los lectores, al tiempo que buscan el disfrute de los mismos y la ganancia económica que conlleva esa popularidad (Walton y Jones 1999, 13). Como tales eventos, los mash-up poseen un valor indudable en la comprensión de la cultura que se consume en un determinado momento y, en este caso, de la relación que esta guarda con aquellos textos canónicos que subvierte.

\subsection{El mash-up como objeto de estudio: la autoconciencia de la literatura popular}

Tomando en consideración las reflexiones anteriores, las tres características esenciales del mash-up son su consciente apropiación y reescritura de un pasado literario, su cuestionamiento del canon entendido como una construcción arbitraria y abierta a crítica (Serazio 2008, 83), y su subversión de las 'jerarquías' que establecen la división entre la 'alta' y la 'baja' cultura (2008, 91). Esta crítica se realiza a través de una reflexión autoconsciente sobre la naturaleza del mash-up como producto cultural de consumo popular y su sátira a la cultura académica, que ensalza unos textos sobre otros.

Por tanto, como parte de su comentario autorreferencial a la posición que ocupan en los márgenes de la literatura canónica, los mash-ups también desarrollan a menudo una aproximación burlesca al lenguaje o trabajo investigador. Un caso especialmente interesante es el de la versión $\mathrm{Z}$ del clásico de García Lorca, La Casa de Bernarda Alba zombi (2009), que lleva años circulando por internet. La versión $\mathrm{Z}$ emplea su peritexto, incluyendo una extensa introducción y el uso de notas al pie que parodian el estilo académico, para vincularse intertextualmente con la que probablemente sea una de sus ediciones más prestigiosas, la de la editorial Cátedra. La elección no es casual, dada la autoridad que se atribuye a las ediciones de esta casa editorial en el mundo del hispanismo. El texto $\mathrm{Z}$ en línea incluso imita la apariencia tradicional de 
los clásicos de Cátedra, la portada negra y las letras blancas, la imagen, la tipografía ${ }^{3}$. Asimismo, en su blog los autores incluyen una serie de entrevistas fictivas y falsas afirmaciones de la editorial, donde se proclama este texto como el primer clásico virtual ${ }^{4}$.

Es relevante mencionar este ejemplo, puesto que junto a Lazarillo $\mathrm{Z}$. Matar zombis nunca fue pan comido (2009) y al posteriormente mencionado Don Quijote Z, conforma las bases de una especie de tradición literaria del mashup español y demuestra que el foco que se pone sobre la parodia académica es una constante en estas obras, pero también lo es en el más prolífico corpus de mash-up que existe en la literatura anglosajona, con lo que pueden establecerse paralelismos entre ambas. Así, por ejemplo, los mash-ups de la autora norteamericana Vera Nazarian también juegan con la noción de la autoridad y la respetabilidad, y su obra Northanger Abbey: Angels and Dragons (2010) se publicitó como llena de «scholarly footnotes and appendices», notas al pie y apéndices académicos. Seth Grahame-Smith, asimismo, incluyó en la edición especial de Pride, Prejudice and Zombies un epílogo paródico bajo la autoría de un supuesto erudito llamado «Dr. Allen Grove of Alfred University». Estos elementos paratextuales parodian ediciones académicas, al tiempo que hacen evidente su propia posición fuera del canon, como obra literaria, o del ámbito académico, como objeto de estudio.

$\mathrm{Y}$ es que, aunque algunos programas de estudio o titulaciones ya incluyen nuevos géneros populares como este, otros niegan el fenómeno editorial y literario que ha supuesto esta forma de hibridación. A pesar del inmenso éxito que ha cosechado entre los lectores - con el libro de Grahame-Smith llegando a ser éxito de ventas del New York Times-, su valor como producto cultural que refleja la preocupación social de su tiempo, su actualización de los temas latentes en los clásicos -desde el empoderamiento femenino a la amenaza de la tecnología (Borham-Puyal 2018)-, o sus ejemplos de inteligente parodia, el mash-up es todavía un género relativamente poco estudiado en el ámbito académico. Volviendo a Pride, Prejudice and Zombies, no solo se trata de un éxito de ventas, sino de un texto que ha generado una franquicia propia y un género enormemente popular, y, sin embargo, su valor cultural todavía se cuestiona. De hecho, Quirk Books, la editorial que publicó la obra de Grahame-Smith, reconoce el (pobre) estatus de sus mash-ups al crear una irónica colección titulada 'Quirk Classics', que imita la apariencia de Penguin Classics pero reconoce con su nombre (quirk=extraño) su posición en los márgenes de los estudios literarios, muy alejado de los clásicos canónicos. No obstante, se podría argumentar que la novela de Grahame-Smith es un clásico $Z$ por derecho propio, si por ello entendemos que no solo es un texto paradigmático, sino también fundacional

3. El e-book está disponible aquí: <http://es.calameo.com/read/0000905411a5e941ec4ee>. Fecha de acceso: 11 de mayo de 2020. La imitación del estilo de Cátedra se hace aparente al instante.

4. <http://bernardaalbazombi.blogspot.com.es/>. Aunque no es parte del fenómeno Z, es relevante también mencionar el Mutatis Mutandis (2010) de Javier García Rodríguez, el cual, desde el título mismo, ofrece una aproximación burlesca al mundo académico y a la idea del canon. 
de un nuevo género, ya que ha inspirado a autores para expandir el universo textual con precuelas, secuelas, películas y videojuegos, y ha dado a escritores posteriores una fórmula que puede repetirse en otros contextos y géneros -algo que podría decirse de clásicos más canónicos como Robinson Crusoe o el mismo Don Quijote-. Por supuesto, no se trata de entrar en una discusión sobre méritos literarios, sino de trazar la creación de un fenómeno de literatura popular que se convierte en un modelo que imitar y que lo hace a hombros de textos que fueron igualmente populares, inmensamente leídos en su día y cuyo estatus como clásicos en ocasiones oscurece esos orígenes.

\subsection{El lugar del ingenioso hidalgo zombi en la tradición quijotesca}

En el contexto del estudio del mash-up, como no podía ser de otra manera, esta contribución se centra en la obra cumbre de Miguel de Cervantes, Don Quijote $(1605,1615)$, un texto paradigmático en su mutabilidad y adaptabilidad. La novela de Cervantes se ha continuado, traducido, imitado y adaptado, en su propio género, en otros géneros y en otros medios, inspirando a poetas, dramaturgos, compositores, coreógrafos y todo tipo de artistas (Riley 1988, 105), convirtiéndose en algo diferente y, sin embargo, permaneciendo de alguna manera constante en cada caso ${ }^{5}$. Esta cualidad homeostática, esta resiliencia o adaptabilidad, se explica por lo que Levin entendió como el proceso básico desarrollado por Cervantes, el quixotic principle o 'principio quijotesco' $(1970,58)$ : un precepto dialógico que permite la coexistencia de suprasistemas opuestos en su obra, sostenidos a través del uso de la ironía y el diálogo incluso entre posturas extremas. En el centro del principio quijotesco uno encuentra cómo diferentes formas de percepción, distintas realidades, entran en contacto en la búsqueda de un significado último ${ }^{6}$. El texto de Cervantes, por tanto, contiene en sí mismo el potencial de incluir distintas perspectivas, diferentes epistemologías o incluso diversos géneros literarios en diálogo ${ }^{7}$, lo que puede explicar sus múltiples adaptaciones en el tiempo y el espacio, así como el impacto que ha tenido y tiene en la cultura contemporánea ${ }^{8}$.

5. James Iffland denomina a esta fórmula que permanece, incluso en su infinita adaptabilidad, un ideologema o, en este caso, un quijotigema. Este quijotigema (1987a, 30) despierta una interpelación universal, una capacidad de atraer a grupos de cualquier posicionamiento ideológico (ibid., 26) y de convertirse en parte y parcela de la 'cultura general' de la civilización occidental (1987b, 21).

6. En palabras de P. J. Pardo: «The quixotic principle incorporates not just the conflict between the romantic imagination and reality, but also between vision and reality, world and worldview, and of course between different visions and worldviews, and therefore implies a representation of reality as a dialogue of perspectives» (2005b, 98-99).

7. En este sentido, J. A. Garrido Ardila caracteriza a la novela de Cervantes por su hibridismo genérico (2001).

8. Sobre la rica recepción de Don Quijote y sus numerosas adaptaciones, véase J. A. Garrido Ardila (2015); Hans C. Hagedorn (2016); Emilio Martínez Mata y María Fernández Ferreiro (2014) 
Una de las adaptaciones más recientes se inscribe en el género del mashup, donde los monstruos permean la obra de Cervantes. Se trata de la novela de 2010 Don Quijote Z, o El ingenioso hidalgo zombi Don Quijote de la Mancha, una reescritura de algunos de los episodios esenciales de la primera parte de la novela, remezclados con literatura $\mathrm{Z}$, en la tradición literaria del amplificatio, de la creación de nuevos universos narrativos basados en el clásico de Cervantes. Aunque a primera vista pueda parecer una aportación poco relevante al universo cervantino, este mash-up quijotesco sigue en la tradición de otras adaptaciones cervantinas al responder a la naturaleza misma del hipotexto, el cual se presta a estas transformaciones, que responden a los cambios temporales, espaciales, sociales, ideológicos o de gustos literarios. El objetivo del presente artículo, pues, será inscribir el nuevo género, el mash-up, en la tradición de adaptaciones quijotescas. Para ello explorará la original apropiación que el mash-up lleva a cabo con Don Quijote, al colonizar el texto canónico con literatura zombi o $\mathrm{Z}^{9}$, a diferencia de otras reescrituras donde el caballero se inserta en nuevos contextos, o donde se crean diversas figuraciones quijotescas. Además, será posible percibir cómo esta invasión del clásico permite un acercamiento satírico tanto a la sociedad como al mundo editorial, sin olvidar la inclusión de la parodia dirigida al género $\mathrm{Z}$. Por tanto, la popularidad de los géneros no impide que el mash-up quijotesco se convierta en parte de una importante tendencia autorreferencial en la cultura y literatura españolas, ejemplificada en el mash-up de otros clásicos. Finalmente, se pretende contribuir al debate sobre el empobrecimiento que supone la hermenéutica de la exclusión, puesto que limita la percepción que se tiene sobre la tradición literaria y la forma de entender la cultura contemporánea. En este sentido, el mash-up quijotesco es un nuevo paso en un rico diálogo intertextual y cultural que se ha desarrollado durante siglos, y que no debería verse limitado por consideraciones canónicas.

\section{DoN QUiJote Z: EL MASH-UP EN LA TRADICIÓN QUIJOTESCA}

En esta versión Z del clásico de Cervantes, don Quijote ha leído demasiadas novelas de zombis y decide marchar por el mundo en busca de los no-muertos.

o Carlos Mata Induráin $(2013 ; 2015)$.

9. Por literatura zombi nos referimos a la tradición posromero, donde es evidente su influencia. Mientras que la literatura zombi anterior se basaba sobre todo en tradiciones clásicas o haitianas, las narrativas $\mathrm{Z}$ contemporáneas tienden a seguir las ya arquetípicas construcciones e interpretaciones del zombi características de la obra de George A. Romero. Escandell-Montiel hace un sucinto pero completo análisis del paso del zombi clásico a través del bokor (el brujo haitiano) y su poder sobre una de las dos almas que tienen las personas: el Gros Bon Ange (la memoria) y el Ti Bon Ange (la espiritualidad), al mito de Caligari y a Romero. Este autor explica el impacto de estos mitos en la cultura contemporánea: la visión haitiana incorpora, por un lado, a los controladores de cuerpos, pero luego la reinvención de Romero a través del concepto vírico/contagioso redefine el zombi (EscandellMontiel 2016, 41-44). 
Lo que sigue es la sustitución de una forma de obsesión literaria por otra, puesto que, al contrario de lo que ocurre en otros mash-ups, el hidalgo no lucha contra los zombificados, sino que cree hacerlo, impulsado por su locura. En este sentido, López Navia ha identificado este texto como un caso único en la tradición hispánica de las adaptaciones cervantinas, ya que no solo parodia un sistema literario muy específico, sino que lo hace desde la misma editorial que se ha dado a conocer por sus narrativas Z, Dolmen $(2014,714)$. Junto a las referencias a las narrativas $\mathrm{Z}$ aparecidas en Dolmen, sus páginas están repletas de alusiones a clásicos del género, desde novelas a películas. Por lo tanto, Don Quijote $Z$ responde a la parodia metaliteraria y autorreferencial que puede encontrarse en el original y en algunas de las reescrituras más canónicas del mismo ${ }^{10}$.

Aunque la naturaleza del héroe se tratará más adelante, es importante destacar la manera en la que, como género, el mash-up continúa en la larga tradición de reescrituras del texto cervantino y participa en la naturaleza híbrida del original. En primer lugar, emplea géneros populares en el momento de la reescritura, los cuales están sujetos al debate crítico y académico. En este caso, se trata de la literatura $Z$, que ha encontrado un lugar en algunos programas académicos, pero que sigue siendo mayoritariamente ignorado fuera del campo de la cultura popular. En su momento, el texto de Cervantes hizo lo mismo, al dialogar con los romances caballerescos al tiempo que incluía en sus páginas diversas formas de géneros populares coetáneos en los relatos intercalados ${ }^{11}$. Y, como ocurrió con el hipotexto, el paródico Don Quijote $Z$ también incluye entre sus páginas dos narrativas $\mathrm{Z}$.

El primero forma parte del peritexto, donde el autor incluye el relato breve «Luna de sangre en Lepanto», escrito por el académico ficticio Gualberto G. Álvarez. Esta historia es un ejemplo interesante de otro tipo de género, denominado faction (fact+fiction), al tratarse de una recreación fictiva de la batalla de Lepanto y de los hechos que condujeron a las famosas heridas de Cervantes ${ }^{12}$. En el relato, Cervantes descubre la existencia de los no-muertos a través de las historias de Isaac, un médico judío, y experimenta la realidad de dichas criaturas cuando rescatan a un náufrago y este le muerde el brazo, resultando en su zombificación y amputación, dando lugar a la famosa manquedad del escritor. Los falsos editores afirman en la introducción que esta historia puede explicar la posterior obsesión de Cervantes por los zombis, lo que resultó en la creación de su novela El hidalgo zombi de la Mancha.

La segunda inclusión de una narrativa $\mathrm{Z}$ ocurre en la tercera salida del hidalgo, cuando el autor asevera que las crónicas orales registran unas batallas contra los infectados:

10. Véase, por ejemplo, Pardo (1996, 2005a).

11. Sobre este tema, Garrido Ardila afirma que Cervantes impregna su novela de todos los subgéneros del romance $(2001,6)$.

12. El interés por la recreación ficcional de la vida de Cervantes ha encontrado eco en otras obras como Cervantes Street (2012) de Jaime Manrique; La sombra del otro (2014) de Luis García Jambrina; o la reciente obra Las Cervantas (2016), de Inma Chacón y José Ramón Fernández. Véase también Edward H. Friedman (2015). 
Pero el autor de esta historia, puesto que con curiosidad y diligencia ha buscado los hechos que don Quijote hizo en su tercera salida contra los no-muertos, no ha podido hallar noticia de ellos, por lo menos por escrituras auténticas; sólo la Fama ha guardado, en las memorias de la Mancha, que don Quijote, la tercera vez que salió de su casa, fue a Zaragoza, donde se halló en unos famosos combates contra un brote de infectados que en aquella ciudad hicieron, y allí le pasaron cosas dignas de su valor y buen entendimiento (333, la cursiva es mía).

De la misma manera que el hidalgo de Cervantes experimentó lo que percibió como combates genuinos en sus salidas posteriores, don Quijote $\mathrm{Z}$ aparentemente encuentra zombis fuera de su imaginación. Como bien ha apuntado López Navia, en esta interrupción narratorial, que se hace eco del original de Cervantes, estamos ante «el único hecho que transciende la dimensión estrictamente literaria del universo zombi para apuntar a una aventura propia del género» $(2014,723)$.

Es verosímil concebir estas inclusiones del género $Z$ como una parodia a los escenarios en los que se suelen desarrollar estas narrativas. Desde novelas $\mathrm{Z}$ a videojuegos y películas, autores y guionistas intentan crear contextos apocalípticos que se nutren de miedos contemporáneos a la tecnología, la ciencia o la avaricia corporativa, cercanos al desencanto o sentido de crisis que puede poseer el público lector. «Luna de sangre en Lepanto» imita esas preocupaciones al fusionar miedos raciales y religiosos que marcaron la época en la que supuestamente está escrita. Las historias de Isaac sobre el origen de los no-muertos se enmarcan en una isla colonizada donde un esclavista blanco es la primera víctima de la zombificación, mientras que el náufrago occidental ha sido convertido por los turcos -tras lo cual Cervantes confunde a sus enemigos turcos con los monstruos, los zombis- ${ }^{13}$. En este híbrido de hechos y ficción, personajes y lugares históricos como el escritor, la isla de Corisco y la realidad del tráfico de esclavos portugués que se llevaba a cabo allí, confluyen, aunque a veces de manera anacronística. Como ocurre en otras narrativas $\mathrm{Z}$, el autor construye un contexto que los lectores pueden reconocer y situar en la historia, así como una explicación para el origen de la infección que sirve a su vez para parodiar las convenciones del género. De hecho, es frecuente en la literatura Z desarrollar narrativas 'factuales' (faction) sobre el origen y desarrollo de la plaga, así como manuales o diarios de supervivencia. Se pretende jugar con la impresión de autenticidad, al proveer un contexto verosímil o referencias a eventos fácilmente comprobables. Como ejemplo paradigmático es necesario nombrar el clásico del género World War Z: an Oral History of the Zombie War (2006) de Max Brooks, modelado sobre los libros de testimonios en primera persona recogidos tras la Segunda Guerra Mundial. Con su parodia zombi, Brooks desarrolla un profundo comentario sobre los temas sociales y políticos que le preocupan de la Norteamérica del

13. En referencia a la evidente lectura poscolonial de las narrativas $\mathrm{Z}$ y de esta en particular, véase Borham-Puyal (2018, 1322-1328). 
siglo XXI. La oralidad de las gestas del hidalgo en Don Quijote Z, el hecho de que no existan registros o «escrituras auténticas» de las batallas reales del caballero contra los infectados, sino que solo hayan quedado los ecos de su fama, remiten a la novela de Brooks y suponen en el contexto de su parodia un comentario sobre la ubicuidad de las narrativas $\mathrm{Z}$ en la cultura popular: ya no es necesario dar más detalles, puesto que son de sobra conocidas las historias de plagas, apocalipsis, y batallas contra los no-muertos, tan llenas de lugares comunes que no hace falta desarrollarlas más para la imaginación de los lectores.

Junto a este diálogo con géneros populares, el mash-up quijotesco también se muestra cervantino en su naturaleza autorreferencial. La novela $\mathrm{Z}$ desarrolla un interesante peritexto que refleja el prefacio del propio Cervantes. Al reproducir los poemas y la dedicatoria del hipotexto, el texto $\mathrm{Z}$ entreteje las convenciones de la prosa de Cervantes con fechas y nombres contemporáneos que hacen referencia a la editorial, Dolmen. Así, por ejemplo, la fe de erratas parodia el lenguaje formal del siglo XVI, al tiempo que asevera que se firmó en 2010 en las oficinas de Dolmen (73). Lo mismo ocurre con la aprobación del «editor y rey», Vicente García, fundador de Dolmen, y los agradecimientos del autor mismo, los cuales fusionan alusiones contemporáneas con un estilo que parodia la prosa del XVI (73-74). Los poemas, por ejemplo, hacen referencia a otros mash-ups $\mathrm{Z}$ y a la prolífica producción $\mathrm{Z}$ de Dolmen. Con un lenguaje vulgar y poca destreza poética, en el primer poema el autor adopta una postura autocrítica hacia su trabajo y su atrevimiento al reescribir semejante clásico, mientras que también hace referencia a las versiones $\mathrm{Z}$ de $E l$ Lazarillo de Tormes o a la fundacional Pride, Prejudice and Zombies, de alguna manera inscribiendo su obra en una nueva forma de tradición literaria, el mash-up zombi (79). Los otros dos poemas contienen el elogio que el cazador de zombis Leblanc hace de don Quijote, y el diálogo entre los dos autores, Cervantes y González, en el que el último se queja burlonamente del hambre que pasa y la crueldad de su editor (80), haciéndose eco de las penurias del propio Miguel de Cervantes. Esta autorreferencialidad también se hará evidente más adelante cuando el autor afirme que el hidalgo prefería leer los libros del famoso «Vicente de Domenalto» (82), o en el encuentro de don Quijote con un escritor de narrativas zombis, quien se queja amargamente de la crueldad de su editor (277-278). Los detalles que este personaje, un cautivo, da de sí mismo, por ejemplo, el hecho de que es un hombre de letras asturiano, le identifican como el alter ego del autor. Las cómicas hipérboles sobre la crueldad del editor y su descripción de las novelas $\mathrm{Z}$ como literatura de encargo o de poca monta, que difiere en gran medida de lo que realmente querría escribir, aumentan la burla, a la vez que permiten vislumbrar la poca consideración que el género $\mathrm{Z}$ tiene en el mundo editorial.

También llama la atención sobre sí mismo el prólogo al lector, en el que el autor explica el proceso de escritura y teme la reacción de los puristas cervantinos (76), debatiendo con un amigo la posibilidad real de publicar un libro semejante. En otra vuelta de tuerca, el autor afirma que no ha hecho más 
que volver al original de Cervantes para recrear la versión zombi de la novela:

... es pretensión mía presentar las cosas así como las he visto y como las he encontrado y después compuesto; y esto es, tal y como esos papeles de este zombificado Quijote fueron hallados por mí en tan discreto comercio, porque es en ellos donde se encuentra la verídica historia del hidalgo, que no quería ser caballero andante sino matador de muertos andantes, que no es misma cosa y que es parecida a un tiempo... (77).

A esto responde su amigo que nadie creerá semejante afirmación o confiará en un libro lleno de sinsentidos zombis. Sin embargo, también le advierte de que la literatura $Z$ es muy conocida y no necesita ninguna razón de ser, puesto que de «libros de zombis y zombificados [...] está ya el Mundo bien lleno» (76), al tiempo que enfatiza que nadie se toma esta forma de literatura en serio, así que le permite actuar con libertad, sabiendo que los lectores lo disfrutarán si así desean hacerlo (76-77). Esta última afirmación señala a la narrativa $\mathrm{Z}$ como un género ampliamente leído, que busca entretener y no se toma demasiado en serio; es una forma literaria en los márgenes de lo canónico que juega con esa posición limítrofe.

Este juego también hace de esta obra algo diferente al resto de las series $\mathrm{Z}$ editadas por Dolmen, puesto que es la reescritura de un clásico, lo que conlleva la reproducción casi literal de algunos de sus episodios y discursos más icónicos, ahora adaptados a la nueva forma de locura o manía del hidalgo -Don Quijote $Z$ explota así su naturaleza liminal, su condición de texto de transición que sirve de puente entre dos novelas, o dos géneros, en diálogo-. Por lo tanto, responde a la concepción de Walter Reed sobre la novela -con Don Quijote como ejemplo paradigmático-, entendida como un género autoconsciente de la existencia de un canon y su posición fuera del mismo, al tiempo que se burla de la idea misma de lo canónico ${ }^{14}$.

De hecho, quizá lo más relevante de Don Quijote $Z$ es su parodia del estatus del hipotexto como un clásico universal y uno de los textos más estudiados en el mundo académico, lo que demuestra una vez más su posición liminal, su orientación hacia el urtexto caracterizada por la distancia y falta de deferencia. Se puede comprobar, por ejemplo, en cómo incluye un comentario acerca de las controversias que han rodeado la atribución y autoría del texto durante siglos. Aquí la posibilidad que se ofrece es que el texto original de Cervantes, efectivamente, presentara al hidalgo como un lector obsesionado con los zombis, pero que el autor lo modificara posteriormente para trans-

14. Walter Reed, empleando un lenguaje bajtiniano de dialogismo y confrontación, identifica el diálogo con tradiciones literarias previas como la característica principal de lo que se denomina la novela; esto es, para Reed la esencia de la novela es su «ethos of opposition [...] the idea of a novelty confronting literary tradition» $(1981,3)$. Reed define este género como «a type of literature suspicious of its own literariness [...] outside the prevailing literary canon but self-consciously aware of it» (ibid. 4, 27). 
formar su manía literaria en una obsesión por los romances caballerescos. Los falsos editores se lanzan entonces a la especulación: si es una falsificación en la línea de Avellaneda o puede tratarse de la clave para entender las diferencias entre la primera y la segunda parte de la obra de Cervantes; si es posible que el autor original de la novela Z sea Házael G. González, ancestro del autor Z contemporáneo, o el mismo Cervantes; y si González, pues, hace uso del texto original de Cervantes o inventa dicha atribución (7-8). Esta parodia académica refleja algunos de los debates que conciernen al texto de Cervantes: la atribución del texto apócrifo de Avellaneda, las diferencias entre las dos partes, el juego de voces autorales y narrativas, etc.

Para desarrollar esta parodia aún más, el autor hace uso de un falso académico: Gualberto G. Álvarez, descrito como catedrático en la Universidad Asturiana de Cerredo y un experto en zombis, así como en todas las formas históricas de los no-muertos (8). Así, el relato «Luna de sangre en Lepanto» se dice que ha sido reconstruido y reescrito a partir de fuentes fiables, aunque incompletas, por dicho académico bufo (9). Por supuesto, dada la inmensa popularidad de Cervantes, y la importancia concedida a su persona y su obra en el mundo académico, la aparición de nueva información sobre su vida habría sido un descubrimiento esencial. Esta revelación hubiera sido debatida y analizada, y el trabajo de Cervantes habría sido examinado bajo la luz de las nuevas aportaciones. Esta es la posibilidad que parodia la reescritura Z, al indicar que solo ahora se entiende el cambio que realizó Cervantes del original $\mathrm{Z}$ al texto que se conocía hasta el momento (9), mientras que Álvarez afirma que ha tenido que entretejer 'Historia' con historias, unificando documentos, para que el lector académico pueda decidir por sí mismo sobre la veracidad de su estudio (69). Siguiendo esta línea paródica, el prefacio de los falsos editores asegura que la suya es una edición crítica y rigurosa, y que corresponde a otros académicos estudiar el texto y juzgar «lo que en ella pueda haber de verdadero o de falso, o de apócrifo o de auténtico, o de vivo o de no-muerto» (9). El prefacio termina con una invitación a los lectores a creer lo que vean conveniente (9), una invitación abierta a ser crítico o simplemente a disfrutar la obra. Finalmente, la novela concluye con el descubrimiento por parte del autor de unos manuscritos perdidos que incluyen un apéndice de los académicos de Argamasilla sobre la muerte de don Quijote, lo que reproduce una vez más el juego de narradores y autores que encontramos en la obra de Cervantes. El autor sigue parodiando el trabajo académico sobre Cervantes al afirmar que los manuscritos que no se pudieron leer se dieron a los eruditos, quienes tienen la intención de publicarlos «a costa de muchas vigilias y mucho trabajo» (335). No obstante, a pesar de todo este trabajo, el autor espera que no continúen con la tercera salida del hidalgo, puesto que, en su opinión, lo que se ha escrito hasta el momento ha sido suficiente.

En conclusión, Don Quijote $Z$ contrapone de esta manera el género popular de la narrativa zombie (la versión contemporánea de los romances de caballería), con la naturaleza de obra canónica de Cervantes y difumina la 
frontera entre la 'alta' y 'baja' cultura, entre un texto académico y un mito universal que ha pasado a formar parte del imaginario colectivo. En ese sentido, Cervantes creó algo más que un clásico, más que los cimientos para el género de la novela moderna. También desarrolló un personaje que se convertiría en un icono, en una figura universalmente reconocible, que se vería reescrita en cualquier género o contexto nacional y cultural. Este personaje, que epitomiza el enfrentamiento entre la realidad y la imaginación, entre el yo y la sociedad, encontraría asimismo expresión en el gusto de la literatura $\mathrm{Z}$ por individuos que deben luchar contra una sociedad zombificada que busca transformar a esos seres únicos en uno más. Por tanto, el mash-up Z será un paso más en el desarrollo del mito quijotesco, asumiendo, además, que los lectores serán capaces de reconocer y empatizar con el singular hidalgo que presenta.

\section{ENTRE LOS MUERTOS Y LOS NO-MUERTOS: LA RESILIENCIA LIMINAL DE DON QUIJOTE}

En 1734, Henry Fielding publicó una obra titulada Don Quixote in England, en la que don Quijote y Sancho se veían literalmente trasladados a Inglaterra. Esta obra era solo uno de los numerosos ejemplos en los que don Quijote se vio adaptado a otros idiomas, culturas o contextos temporales. Esta transposición del mito quijotesco a un contexto cultural diferente se reproduce en el mash-up de Cervantes, pero con una modificación sustancial: el escenario no cambia. El mito quijotesco no se ha inscrito en un país diferente, o en otra época o género literario. Es la novela de Cervantes la que se ha visto invadida por la literatura $\mathrm{Z}$ y el subtexto del siglo XXI que trae consigo. Don Quijote aparece tal y como lo creó Cervantes, y el autor del mash-up simplemente transforma su obsesión con la literatura popular de su momento, romances de caballerías, en un excesivo gusto por las novelas $\mathrm{Z}$ que están en boga. De hecho, mucho de Don Quijote $Z$ es una transcripción casi literal del hipotexto, lo que para algunos críticos resta originalidad a esta recreación ${ }^{15}$. Aunque es imposible negar que hay menos producción innovadora en esta que en otras formas de recreación, es precisamente parte de la naturaleza del género del mash-up el emplear el máximo posible del texto original para, en primer lugar, resaltar la maestría del hipotexto, y, en segundo lugar, para evidenciar la relevancia que todavía posee el subtexto del original, que se actualiza para los lectores contemporáneos. Los mash-ups, por tanto, reclaman autoridad sobre un hipotexto popular -un clásico que lo es porque pertenece al colectivo cultural occidental- y establecen un diálogo cultural con él. Don Quijote $Z$ va incluso más lejos, puesto que no atribuye el sampleado a dos autores, sino

15. Véase López Navia $(2014,718)$. Sobre la 'reapropiación' como característica esencial del mash-up y su significación cultural y política veáse Serazio (2008). 
que el autor contemporáneo media la voz y autoría del creador original. Es decir, donde Grahame-Smith y Winters hablan siempre de colaborar con los autores del pasado, Hazael G. González se permite apropiarse de la historia misma de Cervantes y reescribir el relato sobre la construcción de la novela.

Este cambio en el contexto literario y cultural remite a la ya mencionada intención paródica, y ofrece una interesante aproximación al concepto de autoría, originalidad y la preservación del canon; sin embargo, también está relacionado con la crítica social que presenta el texto. En la novela original, don Quijote promulga los principios de los romances caballerescos que enfatizan conceptos obsoletos como el honor, el valor, o la cortesía, los cuales a su vez cumplen la función de destacar la crueldad o egoísmo de los demás personajes. Las salidas a lo largo y ancho de España permiten a don Quijote ofrecer un análisis comprehensivo de su sociedad, dando su visión liminal o desde el margen de las distintas clases sociales, de los criminales a los Duques. A pesar de que su conducta mueve a la risa, don Quijote se convierte en el medio a través del cual su autor nos permite descubrir la locura que reina en el mundo, y que no es exclusiva del iluso hidalgo. Este papel del quijote como instrumento de crítica social se encuentra reproducido en muchas de las subsiguientes interpretaciones y reescrituras, las cuales desarrollan la doble concepción de don Quijote como lector crédulo y como faro moral, al mismo tiempo medio para y objeto de la sátira (Paulson 1967, 119) ${ }^{16}$. Al permanecer fiel a su visión individual, la figura quijotesca se niega a imitar a su sociedad, es decir, rechaza una forma de mimetismo social y provee alternativas a los suprasistemas estableci$\operatorname{dos}^{17}$, a veces incluso resistiéndose activamente a una (re)integración social.

Esta lectura dual está presente en el don Quijote de Házael G. González. Por una parte, encarna los efectos embrutecedores y regresivos de la obsesión por la literatura Z. Como ocurrió con el personaje de Cervantes, el hidalgo Zombi presenta un caso de locura intermitente, puesto que cuando no sufre un ataque de manía literaria es capaz de razonar y deslumbrar a sus oyentes con su inteligencia. Una ilustración de ello sería su discurso en la posada sobre armas y letras, cuando los demás huéspedes no le hubieran considerado loco o «zombificado» (275). Sin embargo, estos momentos de lucidez solo hacen más penosa la recaída:

Y en todos los que le habían escuchado sobrevino nueva lástima de ver que aquel hombre que, al parecer, tenía buen entendimiento y buen discurso en

16. Aunque hay muchos ejemplos conocidos en la tradición quijotesca británica, los casos del doble propósito de la figura quijotesca también se encuentran en la tradición de las adaptaciones españolas, a la que pertenece Don Quijote Z. Podemos mencionar, entre otros, El culto graduado (1625), de Alonso de Castillo Solórzano, donde el autor ridiculiza a los culteranos, mientras que emplea a su poeta quijotesco para criticar la atmósfera de la corte (Rodríguez Mansilla 2012, 344) y, podríamos añadir, también exponer la crueldad de aquellos que humillan al iluso poeta.

17. Gillian Brown ha establecido la diferencia entre «quixotic mimeticism», el cual emula la ficción, y «social mimeticism», que significa seguir los dictados de la sociedad una vez que la figura quijotesca ha recuperado la cordura $(1999,260)$. Cada forma de mimeticismo o emulación sigue su propio suprasistema. 
todas las cosas que trataba, hubiese perdido tan rematadamente el juicio, en tratándole de su negra y siniestra afición a las cacerías de muertos vivientes (276).

De manera muy relevante, en este pasaje se describe al hidalgo como loco o zombificado por efecto de sus lecturas (275), lo que lo distingue de otros héroes o heroínas de los mash-ups Z. La novela establece en este sentido un paralelismo entre el subtexto habitual de los zombis -seres que son incapaces de pensar por sí mismos- y la falta de juicio o lectura crítica que configura formas tradicionales de quijotismo, ya que don Quijote no lucha contra los no-muertos excepto en su imaginación. Es decir, la literatura puede convertirse en un elemento zombificante si sus resultados son adormecer el intelecto, especialmente si esa forma de literatura popular se ha convertido en un género de culto. En esta autoparodia, Don Quijote $Z$ demuestra que existe un extenso cuerpo de literatura $\mathrm{Z}$, al tiempo que reflexiona sobre el abuso de los lugares comunes, y la ocasional falta de calidad, originalidad y moralidad que se da en este género, y lo hace al reproducir el discurso original del canónigo sobre los romances $(314-315)^{18}$. La crítica de este último podría referirse no solo a las novelas $Z$, sino a toda la cultura zombi, y encontraría eco en los fans de las películas o series Z, desde Warm Bodies (2013) a The Walking Dead (2010-2019), donde se dan una serie de lugares comunes como el gusto por el gore excesivo, los viajes por carretera, o las tensiones entre los supervivientes, así como en las reconocidas parodias del género como son las comedias iZombie (2015-) o Santa Clarita Diet (2017-2019), cuyo humor se nutre en buena parte de los estereotipos del género $\mathrm{Z}$.

No obstante, el autor mismo se reconoce como escritor de obras Z, y está publicando en una editorial famosa por sus exitosas sagas Z. En otra vuelta de tuerca, durante el famoso episodio de la quema de libros por parte del barbero y el cura, el autor del mash-up solo salva de la pira aquellos volúmenes marcados con el símbolo del dolmen, y ensalza las obras y los autores de la editorial del mismo nombre (103-104). Además, incluye una alusión metaliteraria a escándalos editoriales contemporáneos relacionados con la obra Apocalipsis Z, cuyo autor es acusado de no ser «del todo limpio al publicar

18. En la novela se puede leer: «Verdaderamente, señor cura, yo hallo por mi cuenta que son perjudiciales en la república estos que llaman libros de zombis; $y$, aunque he leído, llevado de ocioso y falso gusto, casi el principio de todos los más que hay impresos, jamás me he podido acomodar a leer ninguno del principio al cabo, porque me parece que, cual más cual menos, todos ellos son una misma cosa [...] Y, puesto que el principal intento de semejantes libros sea el deleitar, no sé yo cómo puedan conseguirle, yendo llenos de tantos y tan desaforados disparates; [...] y toda cosa que tiene en sí fealdad y descompostura no nos puede causar contento ninguno. [...] Fuera de esto, son, en el estilo, duros; en las hazañas contra zombis, increíbles; en los amores entre sobrevivientes vivos, lascivos; en las cortesías y buena educación de sus protagonistas, mal mirados; largos en las batallas contra hordas de muertos vivientes, necios en las razones que sostienen quienes sobreviven a los endemoniados, disparatados en los viajes que los supervivientes son capaces de hacer en ellos, y, finalmente, ajenos de todo discreto artificio, y por esto dignos de ser desterrados de la república cristiana, como a gente inútil» (314-315). 
sus zombificadas suciedades» (105), algo que solo fanáticos del género $\mathrm{Z}$ podrían interpretar ${ }^{19}$. Finalmente, la mayoría de estas novelas comenzaron su vida como blogs que tuvieron el éxito suficiente para convertirse en libros impresos, de nuevo destacando el proceso dialógico y la naturaleza intertextual de la novela $Z$, que rebosa con referencias a la cultura $Z$-vista con un canon y tradición propios-. Por lo tanto, Don Quijote $Z$ da un nuevo giro a la naturaleza autorreferencial del texto quijotesco, parodiando el género al que está contribuyendo y enfatizando la extendida presencia que este tiene, así como el universo cultural que ha construido, en el que los lectores pueden igualar el conocimiento extensivo que demuestra don Quijote sobre el mundo literario $\mathrm{Z}-\mathrm{y}$, por tanto, quizá también reproducir su obsesión literaria o zombificación-.

Por otra parte, el autor contextualiza el trabajo a través de su uso de la literatura $\mathrm{Z}$ y de referencias contemporáneas para reproducir la recurrente lectura de las narrativas $Z$ como un reflejo de los males que asolan a la sociedad. Un ejemplo que ilustra esto es el encuentro del hidalgo con Andrés y su amo. Este último está golpeando furiosamente al muchacho y don Quijote le confunde con un no-muerto:

... su rostro estaba tan desencajado por la cólera que se podría jurar que era venenosa espuma lo que caía de su boca y puses y esputos los que manaban de sus narices y sus orejas, mientras que la sangre arrancada al pobre desdichado era la que a él salpicaba y convertía en el vivo retrato de la perfidia y la maldad (89).

El amo se define por su riqueza, se le conoce como «Juan Haldudo el rico», y se le describe como un empleador abusivo que niega el trabajo de Andrés, así como su jornal (91). Ante esta escena, don Quijote afirma que es imposible que esté vivo del todo, pero que es posible evitar la muerte completa a través del razonamiento y la buena voluntad (90). Al principio, el rico amo parece asumir los argumentos del hidalgo, solo para redoblar su cruel castigo una vez que don Quijote se ha marchado. El hecho de equiparar la zombificación con la explotación y la obsesión por lo material no es única de este texto, como se ha indicado anteriormente ${ }^{20}$. Ni tampoco es una crítica nueva, ya que se encontraba en el original de Cervantes. Sin embargo, es

19. La trilogía de Apocalipsis Z (2008-2011), escrita por el pontevedrés Manel Loureiro, comenzó su andadura como un blog y la primera novela tomó forma gracias a la editorial Dolmen. $\mathrm{Al}$ convertirse en éxito, el autor entonces publicó las dos siguientes entregas con otra editorial, Plaza \& Janés, que también reeditó la primera parte. Asimismo, ha sido acusado de plagio por varios críticos del género zombi (veáse la entrevista en <http://zombi-blogia.blogspot.com/2010/02/entrevista-conmanuel-loureiro.html $>$ (fecha de acceso: 15 de mayo de 2020), donde también se trata la cuestión del enfrentamiento con Dolmen).

20. Otro ejemplo, al que hace referencia López Navia, es un largometraje cubano titulado Juan de los muertos, que se ha leído como una alegoría de la explotación de las clases trabajadoras, entre otros temas $(2014,715)$. Podría especularse que el nombre del hacendado hace referencia a esta película. 
interesante constatar que cuando don Quijote se enfrenta al amo por no pagar lo que le debe a Andrés, revierte a emplear castellano contemporáneo al referirse a «euracos» y «euro» (90-91). En el contexto actual de explotación y crisis laboral, este anacronismo no debería interpretarse como un desliz ${ }^{21}$ sino como un intento consciente de establecer paralelismos entre los trasfondos del hipotexto y el hipertexto. Es por esta razón que el estatus mítico de don Quijote es tan importante: la percepción de los lectores de su posición como un parangón del idealismo y una moral superior, su conocimiento de los episodios principales de la novela -incluso si no han leído el texto completo-22, permiten que el subtexto de dichos pasajes salga a la luz.

En este sentido, aunque don Quijote se define como zombificado por la literatura popular, se resiste a la zombificación de los no-muertos que percibe a su alrededor, y permanece fiel a sí mismo hasta la conclusión de la novela $Z$, ya que esta se centra en la primera parte $y$, a diferencia de la segunda parte de Cervantes, no hay renuncias ni cura a su quijotismo, a la vez que no somos testigos de su muerte, sino que solo escuchamos sobre ella. Esta resistencia a la zombificación y la lucha por la individualidad quijotesca es esencial en el contexto de la literatura $Z$. En este género o subcultura, si un nomuerto muerde a un humano este se transforma en una réplica del zombi, en un no-muerto más. Una persona infectada pierde su individualidad y se convierte en parte de una horda descerebrada. En una adaptación quijotesca nozombi, la des-singularización de don Quijote resultaría en su vuelta al mimetismo social, a su lectura de la realidad de acuerdo a lo establecido, y a un rol menos subversivo en su contexto ${ }^{23}$. Sin embargo, también es cierto que en la mayoría de estas reescrituras el quijotismo se percibe como un resultado de la inocencia o benevolencia del personaje, lo que previene que su visión de la realidad se vea distorsionada por algo peor, como el ansia de poder, la codicia o la lujuria ${ }^{24}$. Don Quijote considera que ser mordido y transformado es peor que la muerte, lo que implica la importancia que concede a su identidad particular y, paradójicamente, su obsesión con las novelas Z le hace ser particularmente consciente de este peligro de zombificación social o grupal.

En este sentido, la literatura cumple un doble propósito: no solo sirve como fundamento al quijotismo del personaje y a la parodia de su autor, sino que también forma o entrena al quijote para reconocer otras formas de zombifi-

21. Algo que hace López Navia en este y otros casos $(2014,724)$. De nuevo, creo que una interpretación de estos pasajes desde las ideas tras el género mash-up permiten aducir una intencionalidad en el uso de estos anacronismos.

22. Borham-Puyal (2015a), entre otros, ha demostrado cómo en las versiones más populares y las ediciones infantiles se repiten una serie de episodios clave que han pasado a formar parte del inconsciente colectivo o de la cultura occidental general.

23. Véase Borham-Puyal (2015b), para un estudio de los finales de adaptaciones quijotescas con protagonistas femeninos donde la 'cura' de la visión quijotesca supone esta vuelta al 'redil' social.

24. Todos son males o visiones que pueden encontrarse en los personajes que rodean a los quijotes en reescrituras como Joseph Andrews (1742) de Henry Fielding, Memoirs of Modern Philosophers (1800) de Elizabeth Hamilton o The Infernal Quixote (1801) de Charles Lucas, entre otros muchos. 
cación y, por tanto, se pone al servicio de la intención satírica del autor. Esta última se hace evidente en la plétora de referencias intertextuales contemporáneas que la novela desarrolla, y los lectores de textos $\mathrm{Z}$ serán capaces de reconocer los contextos sociales que están siendo criticados a través de esa zombificación, y que hubieran sido difíciles de encajar en el contexto del siglo XVI en el que se desarrolla el mash-up quijotesco. Así, por ejemplo, el texto emplea referencias a los «residentes» (90), lo que remonta al fanático $\mathrm{Z}$ a la saga de Resident Evil, una exitosa serie de videojuegos que también ha sido adaptada a la gran pantalla. En ella, la zombificación es el resultado de un arma biológica desarrollada por la malvada farmacéutica Umbrella Corporation. En otra velada alusión intertextual, Sancho concluye la narración hablando insistentemente de una isla -la mejor del mundo- libre de zombis y anticipando las historias que todavía se contarán, lo que podría referir a la saga que el editor, Vicente García, había comenzado con Apocalipse Island (2010), un trabajo que también se menciona en el episodio de la quema de libros. En esta ocasión, el apocalipsis zombi tiene como consecuencia que Europa abandona a Sudamérica y África y construye muros de contención. La isla de Mallorca, sede de Dolmen, experimenta un repentino brote de la plaga. Esta serie ofrece con su narrativa $\mathrm{Z}$ una reflexión sobre las políticas reaccionarias y de represión, lo que sería un subtexto obvio para los lectores de otras obras $Z$, en general, y de Dolmen, en particular.

A través de su reescritura quijotesca, por tanto, este mash-up en particular se convierte en un compendio de narrativas $Z$ que pueden resultar atractivas para los lectores recurrentes de literatura zombi, al tiempo que parodia estas manías literarias y géneros populares contemporáneos. Además, como es habitual en la tradición de reescrituras quijotescas, también permite realizar un comentario sobre asuntos políticos o sociales de especial relevancia. Con este enfoque dual, paródico y satírico, y su doble perspectiva, hacia el pasado y el futuro, el mash-up pertenece a este espacio liminal que tan frecuentemente han habitado las adaptaciones quijotescas.

\section{CONCLUSIONES}

Como los zombis que ahora pueblan sus páginas, Don Quijote se resiste a morir. Ha cruzado las fronteras del tiempo, el espacio y los géneros literarios. Su naturaleza como mito ha demostrado ser resiliente a los cambios literarios, culturales, sociales y políticos, y la iconicidad del hidalgo manchego le transforma hasta nuestros días en una presencia recurrente en distintas reescrituras. Don Quijote $Z$ se convierte en una de las más recientes narrativas en esta larga tradición de la recepción y adaptación de la obra cumbre de Cervantes; y comparte con adaptaciones previas su doble intención paródica y satírica, su diálogo de perspectivas, y su naturaleza autorreferencial. 
Sin embargo, también demuestra su originalidad en la radical apropiación que hace del hipotexto: la novela de Cervantes es reescrita y (re)autorizada, mientras sus páginas se llenan de la actual manía por la literatura Z Como sugiere su autor, parte de la novela está viva y parte está no-muerta (9), parte es nueva y el resto es el texto de Cervantes, un clásico inmortal. El estatus canónico de la obra original es el motivo tras su reescritura; sin embargo, también es el objeto a subvertir a través de su colonización por la literatura marginal o popular. El marco académico burlesco apoya esta interpretación, y resalta la naturaleza liminal de la novela $\mathrm{Z}$ en su parodia de las convenciones de los estudios eruditos o críticos. Este mash-up del clásico dialoga con el canon, lo subvierte, al tiempo que explora el concepto de autoridad literaria, la hibridación genérica, y los subtextos de la literatura $Z$.

El mash-up quijotesco, pues, demuestra ser una aportación relevante a la tradición de reescrituras cervantinas, además de contribuir con un título más a los nuevos clásicos del género, de Pride, Prejudice and Zombies a La Casa de Bernarda Alba zombi. Es, por tanto, posible afirmar que el corpus del mash-up español está en proceso de formación y que Don Quijote será, sin duda, una parte significativa del mismo.

\section{BIBLIOGRAFÍA CITADA}

Aguirre, Manuel, Roberta Quance y Philip Sutton, eds. 2000. Margins and Thresholds. An Enquiry into the Concept of Liminality in Text Studies. Madrid: Gateway Press.

Borham-Puyal, Miriam. 2015a. «For the Amusement of the Merry Little Subjects: How British Children Met Don Quixote in the Long Eighteenth Century». Anales Cervantinos XLVII: 179-204. https://doi.org/10.3989/anacervantinos.2015.004.

Borham-Puyal, Miriam. 2015b. Quijotes con enaguas. Encrucijada de géneros en el siglo XVIII británico. Valencia: JPM Ediciones.

Borham-Puyal, Miriam. 2018. «New Adventures in Old Texts: Gender Roles and Cultural Canons in 21st-Century Mash-ups». Journal of Popular Culture 51 (6): 1312-1331.

Brown, Gillian. 1999. "The Quixotic Fallacy». NOVEL: A Forum on Fiction 32 (2): 250273.

Escandell-Montiel, Daniel. 2016. Mi avatar no me comprende. Cartografías de la suplantación y el simulacro. Salamanca: Editorial Delirio.

Fernández Porta, Eloy. 2008. Homo Sampler. Tiempo y consumo en la Era Afterpop. Barcelona: Anagrama.

Friedman, Edward H. 2015. «Assault and Flattery: Don Quijote and Jaime Manrique's Cervantes Street». BHS 92 (8): 913-931.

Garrido Ardila, Juan A. 2001. «Cervantes y la Quixotic Fiction: el Hibridismo Genérico». Cervantes: Bulletin of the Cervantes Society of America 21 (2): 5-26.

Garrido Ardila, Juan A. 2015. «Introducción: El Quijote hoy». BHS 92 (8): 855-860.

González, Házael G. 2010. Don Quijote Z. Palma de Mallorca: Dolmen Editorial.

Hagedorn, Hans C., ed. 2016. Don Quijote en los cinco continentes. Acerca de la recepción internacional de la novela cervantina. Cuenca: Ediciones Universidad de Castilla-La Mancha. 
Iffland, James. 1987a. «On the Social Destiny of 'Don Quixote': Literature and Ideological Interpellation: Part I». The Journal of the Midwest Modern Language Association 20 (1): 17-36.

Iffland, James. 1987b. «On the Social Destiny of 'Don Quixote': Literature and Ideological Interpellation: Part II». The Journal of the Midwest Modern Language Association 20 (2): 9-27.

Levin, Harry. 1970. «The Quixotic Principle: Cervantes and Other Novelists». En The Interpretation of Narrative. Theory and Practice, ed. Morton W. Bloomfield, 45-66. Cambridge: Harvard University Press.

López Navia, Santiago. 2014. «Bajo el signo de la crisis o don Quijote con su tiempo: el Quijote Z de Házael G.». En Comentarios a Cervantes. Actas selectas del VIII Congreso Internacional de la Asociación de Cervantistas, eds. Emilio Martínez Mata y María Fernández Ferreiro, 714-725. Asturias: Fundación M. ${ }^{a}$ Cristina Masaveu Peterson.

Martínez Mata, Emilio y María Fernández Ferreiro, eds. 2014. Comentarios a Cervantes. Actas selectas del VIII Congreso Internacional de la Asociación de Cervantistas. Asturias: Fundación María Cristina Masaveu Peterson.

Mata Induráin, Carlos, ed. 2013. Recreaciones quijotescas y cervantinas en la narrativa. Pamplona: Eunsa.

Mata Induráin, Carlos, ed. 2015. Recreaciones quijotescas y cervantinas en la poesía y el ensayo. Pamplona: Eunsa.

Mulvey-Roberts, Marie. 2014. «Mashing-up Jane Austen: Pride and Prejudice and Zombies and the Limits of Adaptation». The Irish Journal of Gothic and Horror Studies 13: 17-37.

Pardo, Pedro J. 1996. «La novela como juego. La paradoja metaficcional en Cervantes, Fielding y Sterne». En Paisaje, Juego y multilingüismo. Actas del X Simposio de la Sociedad Española de Literatura General y Comparada, eds. Darío Villanueva y Fernando Cabo Aseguinolaza, 203-217. Santiago de Compostela: Universidad.

Pardo, Pedro J. 2005a. «Cervantes, la novela y la metanovela». En El hidalgo fuerte: siete miradas al Quijote, ed. Alberto Rivas Yanes, 107-142. Luxemburgo: Círculo Cultural Antonio Machado.

Pardo, Pedro J. 2005b. «Tobias Smollett's Humphry Clinker and the Cervantine Tradition in Eighteenth-Century English Fiction». En Cervantes in the English-Speaking World: New Essays, eds. Darío Fernández-Morera y Michael Hanke, 81-106. Barcelona: Reichenberger.

Paulson, Ronald. 1967. Satire and the Novel in Eighteenth-Century England. New Haven: Yale University Press.

Reed, Walter L. 1981. An Exemplary History of the Novel: The Quixotic versus the Picaresque. Chicago: The University of Chicago Press.

Riley, Edward C. 1988. «Don Quixote: from Text to Icon». Cervantes: Bulletin of the Cervantes Society of America 8: 103-115.

Rodríguez Mansilla, Fernando. 2012. «Un Quijote culterano. El culto graduado de Alonso de Castillo Solórzano». BHS 89 (4): 331-345.

Serazio, Michael. 2008. «The Apolitical Irony of Generation Mash-Up: A Cultural Case Study in Popular Music». Popular Music and Society 31 (1): 79-94.

Soto, Isabel. 2000. «Introduction». En A Place that is Not a Place. Essays in Liminality and Text, ed. Isabel Soto, 7-16. Madrid: The Gateway Press.

Walton, Priscilla L. y Manina Jones. 1999. Detective Agency: Women Rewriting the HardBoiled Tradition. Berkeley y Los Ángeles: University of California Press.

Winters, Ben H. 2010a. «I Write with Dead People: How to Collaborate with a Corpse». Huffington Post 18 de marzo. Accesible en: <https://www.huffpost.com/entry/iwrite-with-dead-people_b 347365>. 
LA RESILIENCIA DEL MITO QUIJOTESCO: DON QUIJOTE Z O EL MASH-UP DEL CLÁSICO • 55

Winters, Ben H. 2010b. «Interview». Jane Austen Today 17 de junio. Accesible en: <http:// janitesonthejames.blogspot.com/2010/06/interview-with-ben-winters-author-of.html>.

Recibido: 25 de julio de 2019

Aceptado: 15 de marzo de 2020 
